\title{
AVALIAÇÃO DO ASPECTO SUPERFICIAL E DA EXOTERMIA DE RESINAS RESILIENTES
}

\section{ASSESSMENT OF RESILIENT RESINS SURFACE AND EXOTERMIC REACTION}

\author{
Dalva Cruz Laganá* \\ Newton Sesma" \\ Américo Mendes Carneiro Júnior*** \\ Rafaela Pagin Lourenço ${ }^{* . * \ldots}$
}

\begin{abstract}
RESUMO
Introdução: Devido à preocupação com a influência da topografia da resina na retenção mecânica de microrganismos na superfície da prótese, este trabalho se propõe analisar e discutir o desempenho de quatro marcas comerciais de resinas resilientes para uso clínico, quanto à lisura superficial e sua exotermia. Métodos: Foram preparadas 80 amostras de 4 marcas comerciais, sendo 20 amostras de cada grupo: Grupo A (resina Coe-Soft), Grupo B (resina Dentusoft), Grupo C (resina Soft Confort Dencril) e Grupo D (resina Trusoft). As amostras foram observadas em microscópio ótico com relação ao seu aspecto superficial exotermia da reação de polimerização foi aferida por termômetro de radiação infravermelha. Resultados e Conclusões: Observadores concluíram que o Grupo C apresentou um aspecto superficial mais regular e uniforme e que todos os grupos são seguros em mucosa oral por não apresentarem exotermia significativa.
\end{abstract}

DESCRITORES: Propriedades de superfície • Reembasadores de prótese dentária • Prótese dentária

\section{ABSTRACT}

Introduction: Due to concern about the influence of the topography of the resin in mechanical retention of microorganisms on the surface of the prosthesis, this study proposes to examine and discuss the performance of four commercial brands of resilient resins for clinical use as surface smoothness and its exothermicity. Methods: It have been prepared 80 samples of four commercial brands, 20 samples from each group: group A (resin CoeSoft), group B (resin Dentusoft), group C (resin Soft Confort Dencril) and group D (Trusoft resin). The specimens were observed by an optical microscope with respect to their surface appearance and the exothermicity of the reaction was measured by infrared radiation thermometer. Results and conclusion: Observers concluded that group $C$ had a surface appearance more regular and uniform and that all groups are safe in the oral mucosa for not having a significant exotherm.

DESCRIPTORS: Surface properties • Denture liners • Dental prosthesis

\footnotetext{
* Professora Titular do Departamento de Prótese da Faculdade de Odontologia da Universidade de São Paulo - FOUSP

** Professor Doutor do Departamento de Prótese da Faculdade de Odontologia da Universidade de São Paulo - FOUSP

*** Mestre e Doutor em Dentística- Faculdade de Odontologia da Universidade de São Paulo - FOUSP

**** Aluna de graduação da Faculdade de Odontologia da Universidade Cidade de São Paulo - UNICID
} 
LAGANÁ DC

SESMA N

CARNEIRO JÚNIOR AM:

LOURENÇO RP

AVALIAÇÃO

DO ASPECTO

SUPERFICIAL E

DA EXOTERMIA

DE RESINAS

RES I LIENTES:

24

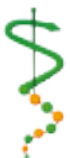

REVISTA DE ODONTOLOGIA DA UNIVERSIDADE CIDADE DE SÃO

PAULO

$2011 ; 23(1):$

$23-9, J A N-A B R:$

\section{IN T RO DUÇ ÃO}

Com o aumento da longevidade, tornase cada vez maior a população idosa em todo o mundo. No Brasil, a principal característica do crescimento do grupo populacional com mais de 65 anos é a rapidez com que o mesmo se processa. As projeções indicam que o país inicia o século XXI com a população idosa crescendo quase oito vezes mais que a de jovens e quase duas vezes mais que a população em geral (Marchini et al. $\left.{ }^{1}, 2001\right)$. Junta-se a esse dado o fato de $15 \%$ (cerca de 25 milhões de pessoas) da população brasileira ser totalmente desdentada e muitos não terem acesso à informação e programas educacionais (Pinheiro², 2001).

Essa faixa etária de pacientes geralmente apresenta peculiaridades que demandam uma atenção especial para sua condição de saúde geral e bucal. Com o aumento da vida média, o conceito de qualidade de vida torna-se mais importante e a saúde bucal tem papel relevante para o idoso, uma vez que o comprometimento da saúde bucal pode afetar negativamente seu bem-estar físico, mental e social.

Uma preocupação crescente dos pesquisadores é a influência da topografia da resina na retenção mecânica de microrganismos na superfície da prótese (Nikawa et al. $\left.{ }^{3}, 2003\right)$. Vários trabalhos comprovaram que a resina apresenta irregularidades que favorecem a colonização por bactérias e fungos e indicaram que uma superfície lisa é fundamental para o controle da placa (Radford et al. ${ }^{4}, 1998$, Taylor et al. ${ }^{5}$, 1998, Verran e Maryan' ${ }^{6}$, 1997).

O acúmulo de placa bacteriana no dorso da sela provoca o aparecimento da estomatite protética. Com isso, mais de $70 \%$ dos indivíduos portadores de próteses totais apresentam essa lesão na mucosa subjacente à base protética, o que desencadeia o processo de reabsorção óssea do rebordo residual no qual a prótese se assenta (Zanetti et al. $\left.{ }^{7}, 1996\right)$. Sabe-se do grande prejuízo que isso representa, pois à medida que a reabsorção ocorre, maior a dificuldade para se manter a estabilidade da prótese na boca do paciente. A falta de estabilidade gera desconforto e altera substancialmente o processo mastigatório, pela alteração da quebra e absorção dos alimentos, causando comprometimento geral do organismo.

Como a maioria das doenças infecciosas envolve inicialmente a colonização e penetração das superfícies mucosas por microrganismos, é de suma importância promover a proteção necessária nessa etapa.

Os materiais resilientes, devido às suas propriedades viscoelásticas, agem como absorventes de impactos, reduzindo e distribuindo as cargas mastigatórias para os tecidos adjacentes às próteses. Seu uso oferece mais conforto ao paciente e tem sido indicado para reembasamento de próteses totais e parciais removíveis após a instalação de implantes (Garcia e Jones ${ }^{8}$, 2004). Entretanto, apesar desses atributos positivos, a colonização de fungos e bactérias na superfície desse material pode resultar em infecções da mucosa, como a estomatite protética, além de candidoses orais, gastrointestinais e pulmonares $(\mathrm{Ni}-$ kawa et al. ${ }^{9}, 1998$, Nikawa et al. ${ }^{10}, 2000$, Pires et al. ${ }^{11}, 2002$ ).

Quando do emprego da técnica de reembasamento direto, a temperatura gerada pela resina decorrente da exotermia da reação de polimerização não deve agredir os tecidos orais. Alem disso as resinas resilientes devem ter um caráter temporário na boca, pois seu grau de porosidade é maior, o que promove maior acúmulo de microrganismos em sua estrutura, tornando-a imprópria para o uso em períodos de tempo mais prolongados.

Diante disso, este trabalho avaliou tanto a exotermia de resinas resilientes indicadas para reembasamentos diretos quanto o aspecto superficial dessas resinas.

\section{MÉTODOS}

\section{Confecção dos corpos de prova}

Foram preparadas 80 amostras de 4 marcas comerciais de resinas resilientes autopolimerizáveis, divididas em 2 conjuntos de 40 amostras, sendo que, em cada conjunto, 10 amostras formavam o Grupo A, com a resina CoeSoft (GC América Inc., Chicago, IL, EUA), 10 do Grupo B, com a resina Dentusoft (Dental Medranos S.A., Buenos Aires, Argentina), 10 do 
Grupo C, com a resina Soft Confort Dencril (Dencril Com. e Ind. de Plásticos Ltda., Caieiras, São Paulo, Brasil) e 10 do Grupo D, com resina Trusoft (Harry J. Bosworth Company, Skokie, Illinois, EUA). Os componentes de todas as marcas apresentamse na forma de pó e líquido (Figura 1).

O primeiro conjunto de 40 amostras foi utilizado para observação em microscópio e avaliação da superfície das resinas. O segundo conjunto de 40 amostras foi empregado na verificação de temperatura de polimerização, sendo que todos os corpos de prova foram preparados segundo as recomendações dos fabricantes.

Para a confecção dos espécimes do primeiro conjunto foram misturados pó e líquido da resina em um recipiente plástico descartável, vertendo-se, a mistura dentro do montador de corpo de prova, com $32 \mathrm{~mm}$ de diâmetro (Extec fast mounting cups, modelo PK/10, Extec Corp., EUA). Esses corpos de prova foram imersos em um plastificador de godiva com água à temperatura de $35^{\circ} \mathrm{C} / 36^{\circ} \mathrm{C}$ para simular as condições bucais e deixados pelo tempo recomendado pelos fabricantes. Após esse tempo de imersão em temperatura bucal, os corpos de prova foram removidos do plastificador e mantidos sobre a bancada para complementar a polimerização.

O segundo conjunto de amostras foi deixado polimerizando no interior do montador de corpo de prova sobre a bancada, sem imergi-los em água, para não haver interferência na aferição da temperatura máxima de polimerização.

\section{Observação da superfície da resina em microscópio}

Após a presa final, os corpos de prova de resina foram removidos do interior do montador de corpos de prova e observados em microscópio ótico de 40x de aumento, equipado com epifluorescência (Nikon E-800, Tókio, Japão), no Laboratório de Ciências da Universidade Cidade de São Paulo.

Dois observadores calibrados analisaram por duas vezes a superfície da resina que ficou em contato com a base lisa do dispositivo para montagem de corpos de prova, sem conhecer qual grupo estavam avaliando, e selecionaram dois espécimes de cada grupo: um com o aspecto mais rugoso e o outro com o aspecto mais liso.

Esses espécimes foram fotografados com câmera digital de 10 Megapixel (Canon, Rebel-XTi) e aumento de 5 vezes para efeito de comparação entre os grupos.

\section{Avaliação da temperatura durante a polimerização}

A temperatura inicial de cada corpo de prova foi aferida pelo Termômetro de Radiação Infravermelha (Eurotron, modelo Miniray 100XL, com Certificado de Calibração LAPIR 033/10, emitido pelo INMETRO), no momento em que a resina foi vertida dentro do montador de corpos de prova. Durante todo o processo de polimerização da resina, a temperatura foi aferida de 30 em 30 segundos e os valores máximos da temperatura comparados à temperatura inicial.

\section{RESULTADOS E DISCUSSÃO}

\section{Temperatura de polimerização}

As médias das temperaturas iniciais e finais máximas dos corpos de prova estão representadas na Tabela 1 . Foi observado um comportamento semelhante em todos os corpos de prova, sem aumento significativo de temperatura que pudesse caracterizar uma reação exotérmica da resina.

Diante desses resultados, pode-se considerar que a polimerização de qualquer uma das marcas de resina resiliente avaliadas (nacionais e importadas) pode ocorrer dentro da cavidade oral dos pacientes de maneira segura para os tecidos orais.

Apesar do alto índice de pessoas parcial e/ou totalmente desdentadas presentes na população brasileira, muitos são os fatores que interferem para que esse sério problema seja de difícil resolução, quais sejam: extensão territorial do país e suas características político-sociais-regionais; situação econômica da maior parte dessa população; falta de um programa governamental mais efetivo na área da prevenção; a falta e a pletora dos profissionais cirurgiões-dentistas nas diversas regiões, tanto nas mais desenvolvidas como nas mais carentes; a falta de melhor formação desses profissionais pelas universidades promovendo uma visão mais social (Marchini et al. $\left.{ }^{1}, 2001\right)$.
LAGANÁ DC SESMA N CARNEIRO JÚNIOR AM LOURENÇO RP

AVALIAÇÃO DO ASPECTO SUPERFICIAL E DA EXOTERMIA DE RESINAS RES I LIENTES

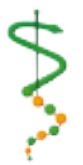

ReVISTA DE ODONTOLOGIA DA Universidade Cidade de são PAulo 2011; 23(1): 23-9, JAN-ABR 
LAGANÁ DC

SESMA N

CARNEIRO JÚNIOR AM

LOURENÇO RP

AVALIAÇÃO

DO ASPECTO

SUPERFICIAL E

DA EXOTERMIA

DE RESINAS

RES I LIENTES

\section{ISSN 1983-5183}

Aliam-se a tais fatores as deficiências encontradas pelas empresas nacionais que atendem ao mercado odontológico no suprimento de materiais necessários à restauração dos arcos dentais. Estas, geralmente, são microempresas, que não possuem respaldo nas pesquisas em busca de uma tecnologia que as tornem competitivas com os fabricantes externos. Além do mais, existe outro fator social que é o da não geração de empregos à população brasileira, dado que o espaço é ocupado pelas estrangeiras. Dessa forma, os cirurgiões-dentistas ficam à mercê dos produtos importados, que possuem, de modo geral, preços elevados, não condizentes com a situação econômica e social da população necessitada.

Atualmente, as resinas disponíveis no mercado são importadas, e acarretam um elevado custo desse material. Consequentemente, grande parcela da população não tem acesso aos benefícios que a resina pode oferecer, como nos casos de hiperplasias, reembasamentos pós-cirúrgicos e outros procedimentos, causando impactos sociais negativos no grande número de pacientes portadores de prótese (Pinheiro $\left.{ }^{2}, 2001\right)$.

\section{Análise comparativa do aspecto su- perficial das resinas}

As figuras a seguir representam dois espécimes de cada grupo, selecionados pelos observadores, sendo um com o aspecto mais liso e o outro, com o aspecto mais rugoso (Figuras 2 a 5).

As amostras apresentaram poucas diferenças quanto a porosidades quando examinadas ao microscópico ótico. Esse resultado pode ter ocorrido devido ao rigor aplicado na manipulação das resinas, seguindo as orientações dos fabricantes.

Nesse sentido, a manipulação da resina Soft Confort requer atenção especial, pois de acordo com as recomendações do fabricante, se o profissional desejar maior rigidez e resistência da resina, esta deve ser colocada em água a $100^{\circ} \mathrm{C}$ por $10 \mathrm{~min}$. Esse procedimento é de difícil realização dentro de um consultório e pode levar à formação de poros se a temperatura ultrapassar $100.8^{\circ} \mathrm{C}$, devido à evaporação de monômeros residuais (Anusavice ${ }^{12}, 1998$ ).

Tabela 1: Média das temperaturas iniciais e máximas dos corpos de prova

\begin{tabular}{ccc} 
Resinas & $\begin{array}{c}\text { Média das } \\
\text { temperaturas } \\
\text { iniciais }\end{array}$ & $\begin{array}{c}\text { Média das } \\
\text { temperaturas } \\
\text { máximas }\end{array}$ \\
Coe- Soft & $23,4^{\circ} \mathrm{C}$ & $23,5^{\circ} \mathrm{C}$ \\
Dentusoft & $24,4^{\circ} \mathrm{C}$ & $24,4^{\circ} \mathrm{C}$ \\
Soft Confort & $22,6^{\circ} \mathrm{C}$ & $22,7^{\circ} \mathrm{C}$ \\
Trusoft & $22,9^{\circ} \mathrm{C}$ & $23,0^{\circ} \mathrm{C}$ \\
\hline
\end{tabular}

Figura 1: Distribuição dos corpos de provas nos grupos de pesquisa
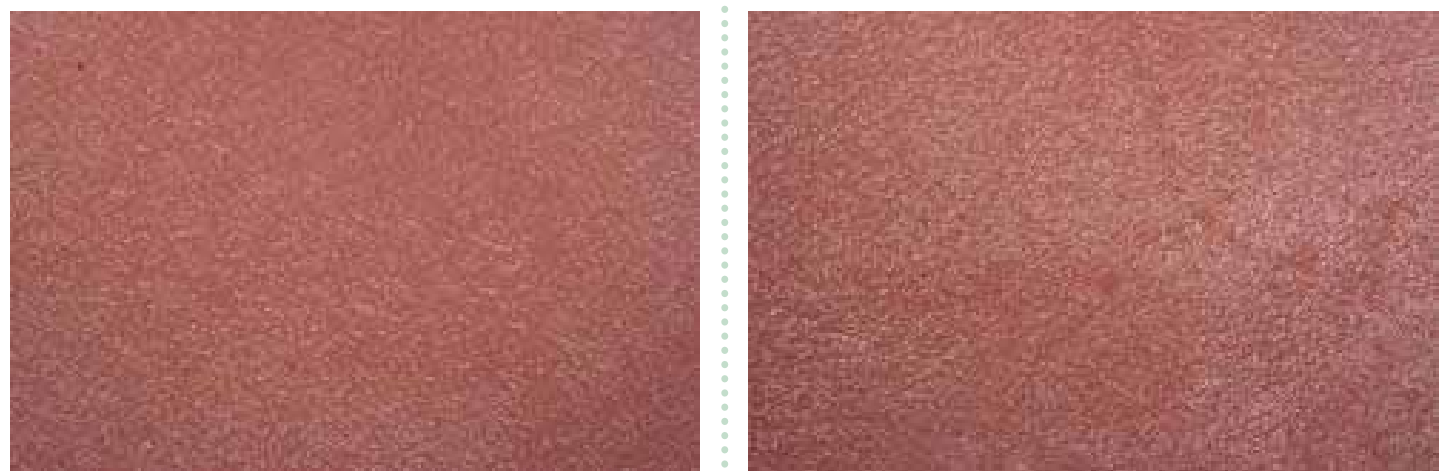

Figura 2: Grupo A - Resina Coe Soft: aspecto liso (esquerda); e aspecto rugoso (direita) 
Apesar de ser o único material, até o momento, empregado na confecção de bases protéticas, a resina acrílica apresenta alguns inconvenientes quando em uso na cavidade oral dos pacientes, inerentes ao próprio material: é um isolante térmico, portanto impede as sensações de calor e frio dos alimentos e acumula placa bacteriana no seu interior por ser uma estrutura porosa, como mostram as pesquisas realizadas com observação em microscopia eletrônica de varredura (Feltrin ${ }^{13}, 1989$, Sesma $^{14}$, 2002). Essa porosidade observada nesses estudos clínicos não foi compartilhada no presente estudo realizado em laboratório com observações em microscópio ótico.

Ainda, segundo a avaliação dos observadores, os corpos de prova do Grupo C (Soft Confort Dencril) apresentaram uma
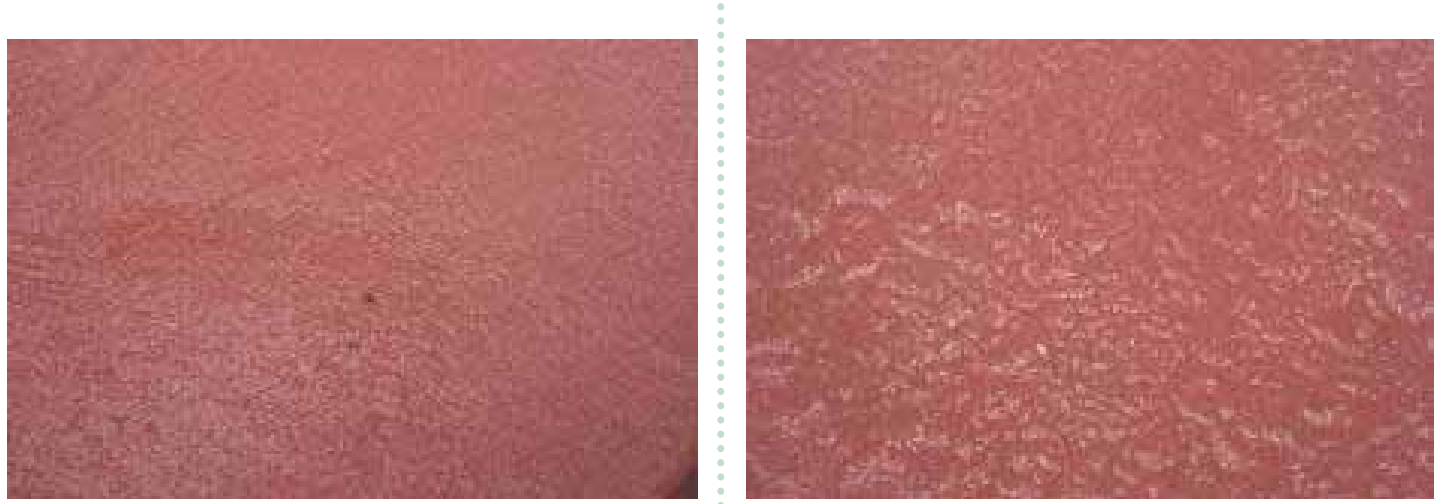

Figura 3: Grupo B - Resina Dentusoft: aspecto liso (esquerda) e aspecto rugoso (direita)
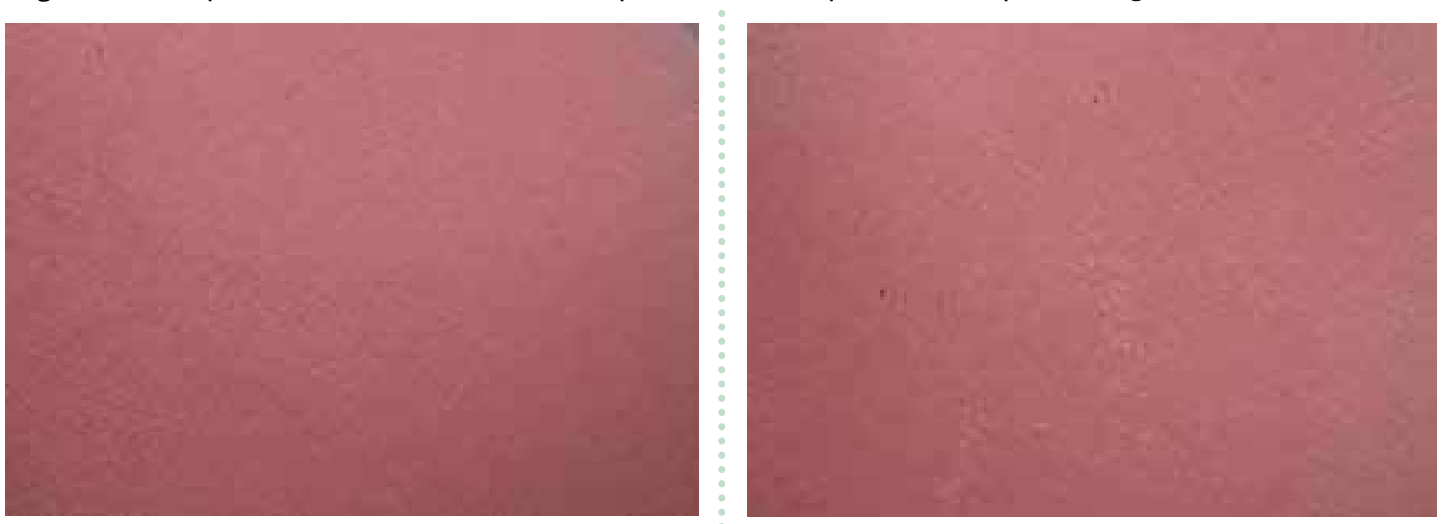

Figura 4: Grupo C - Resina Soft Confort Dencril: aspecto liso (esquerda) e aspecto rugoso (direita)

superfície mais uniforme e regular com maior lisura superficial quando comparados aos demais grupos.

Este estudo apresentou o comportamento de resinas resilientes in vitro. É de extrema importância que uma investigação clínica avalie se a lisura superficial observada nos corpos de prova irá refletir em menor colonização bacteriana dessas resinas.

\section{CONCLUSÕES}

Nenhuma das resinas estudadas apresentou exotermia, sendo, por isso, seguras para uso em mucosa bucal.

$\mathrm{Na}$ avaliação da superfície das resinas, os observadores indicaram que a resina Soft Confort Dencril (Grupo C) apresentou um aspecto mais regular, uniforme e liso, quando comparada aos outros grupos.
LAGANÁ DC

SESMA N

Carneiro Júnior am

LOURENÇO RP

AVALIAÇÃO

DO ASPECTO

SUPERFICIAL E

DA EXOTERMIA

DE RESINAS

RESILIENTES

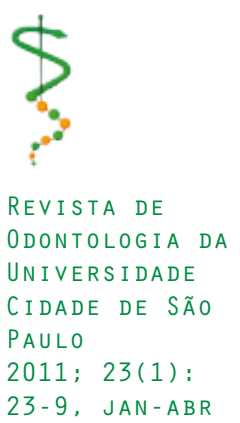


LAGANÁ DC

SESMA N

CARNEIRO JÚNIOR AM

LOURENÇO RP

AVALIAÇÃO

DO ASPECTO

SUPERFICIAL E

DA EXOTERMIA

DE RESINAS

RES I LIENTES
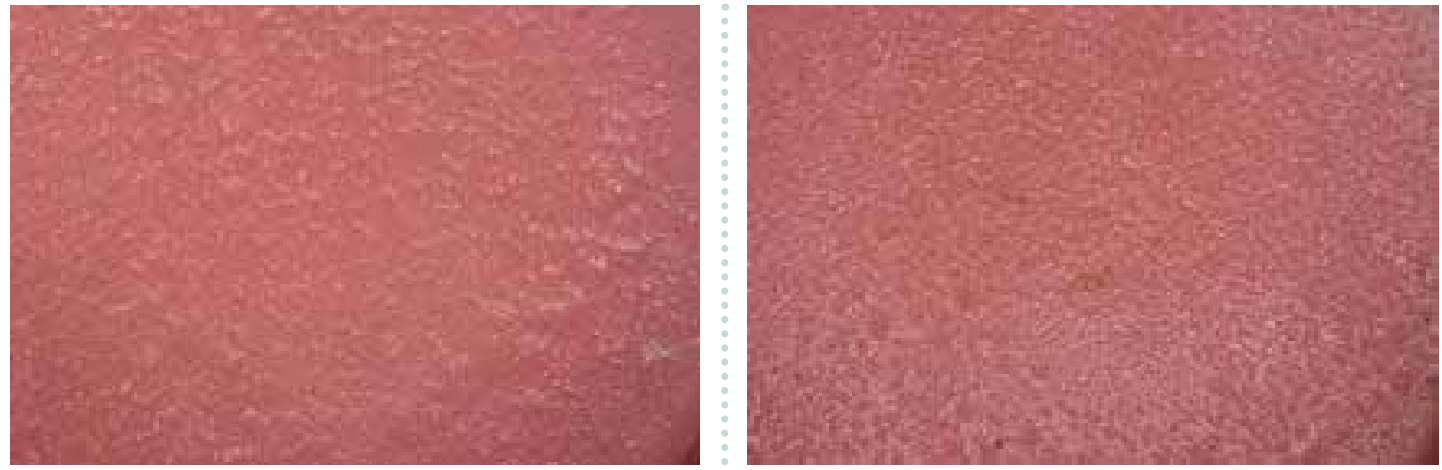

Figura 5: Grupo D - Resina Trusoft: aspecto liso (esquerda) e aspecto rugoso (direita)

\section{REFERÊNCIAS}

1. Marchini L, Montenegro FLB, Cunha VPP, Santos JFF. Prótese dentária na terceira idade Rev Assoc Paul Cir Dent 2001 mar.-abr.;55(2):83-7.

2. Pinheiro C. Soluções para quem perdeu (todos) os dentes. Rev Assoc Paul Cir Dent 2001 55(2):73-81.

3. Nikawa $\mathrm{H}$, Jin $\mathrm{C}$, Makihira $\mathrm{S}$, Egusa $\mathrm{H}$, Hamada $\mathrm{T}$, Kumagai $\mathrm{H}$. Biofilm formation of Candida albicans on the surfaces of deteriorated soft denture lining materials caused by denture cleansers in vitro. J Oral Rehabil 2003 Mar;30(3):243-50.

4. Radford DR, Challacombe SJ, Walter JD. Adherence of phenotypically switched Candida albicans to denture base materials. Int J Prosthodont 1998 Jan-Feb;11(1):75-81.

5. Taylor RL, Verran J, Lees GC, Ward AJ. The influence of substratum topography on bacterial adhesion to polymethyl methacrylate. J Mater Sci Mater Med 1998 Jan;9(1):17-22.

6. Verran J, Maryan CJ. Retention of Candida albicans on acrylic resin and silicone of different surface topography. J Prosthet Dent 1997 May;77(5):535-9.

7. Zanetti RV, Zanetti AL, Laganá DC, Feltrin PP. Estudo de 60 pacientes portadores de prótese parcial removível: avaliaçäo clínica das lesões nas áreas de suporte da mucosa bucal RPG rev pos-grad 1996 jul.-set.;3(3):175-84.

8. Garcia LT, Jones JD. Soft liners. Dent Clin North Am 2004 Jul;48(3):709-20, VII.

9. Nikawa H, Hamada T, Yamamoto T. Denture plaque--past and recent concerns. J Dent 1998 May;26(4):299-304.

10. Nikawa $\mathrm{H}$, Jin $\mathrm{C}$, Hamada T, Murata $\mathrm{H}$. Interactions between thermal cycled resilient denture lining materials, salivary and serum pellicles and Candida albicans in vitro. Part I. Effects on fungal growth. J Oral Rehabil 2000 Jan;27(1):41-51.

11. Pires FR, Santos EB, Bonan PR, De Almeida OP, Lopes MA. Denture stomatitis and salivary Candida in Brazilian edentulous patients. J Oral Rehabil 2002 Nov;29(11):1115-9.

12. Anusavice KJ. Phillips materiais dentários. Rio de Janeiro: Guanabara Koogan; 1998.

13. Feltrin PP. Estomatite protética: estudo da superfície interna da prótese total mucosuportada (microscopia eletrônica de varredura) e da mucosa bucal de suporte (citológico, histopatológico e imunohistoquímico) [Tese]. São Paulo: Universidade de São Paulo. Faculdade de Odontologia; 1989. 
14. Sesma N. Avaliação da eficiência dos métodos de desinfecção de bases protéticas, irradiação por microondas e imersão em solução efervescente enzimática, por meio de análise microbiológica, clínica e microscopia eletrônica de varredura: estudo in vivo [Tese]. São Paulo: Faculdade de Odontologia da USP; 2002.

Recebido em: 30/09/2009
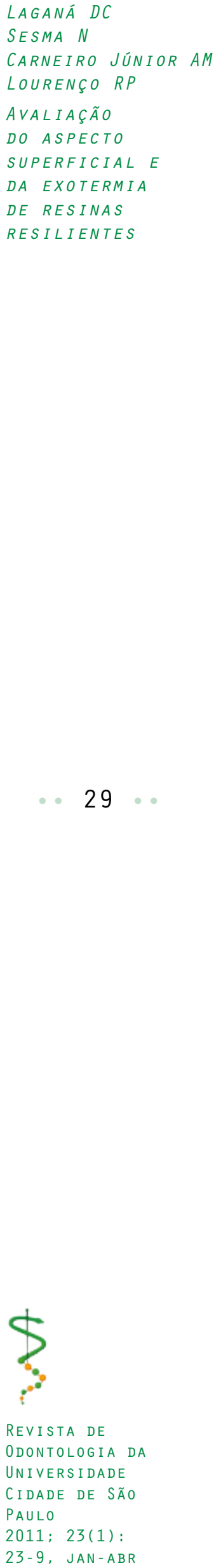